Case Report

\title{
Visceral Leishmaniasis: A Differential Diagnosis to Remember after Bone Marrow Transplantation
}

\author{
Margarida Dantas Brito, ${ }^{1}$ Fernando Campilho, ${ }^{1}$ Rosa Branca, ${ }^{1}$ Carlos Pinho Vaz, \\ Cristina Silva, ${ }^{2}$ Teresa Sousa, ${ }^{2}$ Carlos Mendes, ${ }^{2}$ and António Campos ${ }^{1}$ \\ ${ }^{1}$ Bone Marrow Transplantation Service, Instituto Português de Oncologia Francisco Gentil, Rua Dr. António Bernardino de Almeida, \\ 4200-072 Porto, Portugal \\ ${ }^{2}$ Laboratory of Hematology, Instituto Português de Oncologia Francisco Gentil, Rua Dr. António Bernardino de Almeida, \\ 4200-072 Porto, Portugal
}

Correspondence should be addressed to Margarida Dantas Brito; ana.margarida.dantas@gmail.com

Received 18 September 2014; Accepted 23 November 2014; Published 11 December 2014

Academic Editor: Massimo Gentile

Copyright (C) 2014 Margarida Dantas Brito et al. This is an open access article distributed under the Creative Commons Attribution License, which permits unrestricted use, distribution, and reproduction in any medium, provided the original work is properly cited.

\begin{abstract}
Leishmania infection in immunocompromised hosts is reported in the literature, mostly concerning human immunodeficiency virus infected patients. It is not well characterized in the context of stem cell transplantation. We report a rare case clinical case of visceral leishmaniasis after allogeneic bone marrow transplantation. A 50-year-old Caucasian male was referred to allogeneic bone marrow transplantation with a high-risk acute lymphoblastic B leukemia in first complete remission. Allogeneic SCT was performed with peripheral blood stem cells from an unrelated Portuguese matched donor. In the following months, patient developed mild fluctuating cytopenias, mostly thrombocytopenia (between 60 and $80 * 10^{9} / \mathrm{L}$ ). The only significant complaint was intermittent tiredness. The common causes for thrombocytopenia in this setting were excluded-no evidence of graft versus host disease, no signs of viral or bacterial infection, and no signs of relapsed disease/dysplastic changes. The bone marrow smear performed 12 months after transplantation revealed an unsuspected diagnosis: a massive bone marrow infiltration with amastigotes.
\end{abstract}

\section{Introduction}

Leishmaniasis is an emerging infectious disease, with increasing reports in endemic and nonendemic countries [1]. Additionally, in the past years, some case reports of leishmania infection in immunocompromised hosts appeared in the literature. Most reports refer to HIV infected patients or clinical cases in the setting of solid organ transplantation. There are scarse reports in the context of stem cell transplantation (SCT) [2-4]. The aim of this case report is to present a case of visceral leishmaniasis after allogeneic SCT.

\section{Case Presentation}

A 50-year-old Caucasian male, with no relevant past medical records, was referred to SCT with a high-risk acute lymphoblastic B leukemia in first complete remission (CR). Allogeneic SCT was performed with peripheral blood stem cells from an unrelated Portuguese matched 9/10 donor (disparity in locus HLA-A), after myeloablative conditioning regimen (with busulfan, cyclophosphamide, and antilymphocytic serum). Graft versus host disease prophylaxis was performed with tacrolimus and methotrexate. There were no major complications during neutropenic period. Corticotherapy was prescribed for upper digestive graft versus host disease diagnosed 2 months after SCT. In the following months, patient developed mild fluctuating cytopenias, mostly thrombocytopenia (between 60 and $80 * 10^{9} / \mathrm{L}$ ). The only significant complaint was intermittent tiredness. Bone marrow evaluation had no signs of relapse disease and patient had complete chimerism. The common causes for thrombocytopenia were excluded-no evidence of graft versus host disease; no signs of viral or bacterial infection; and no signs of relapsed disease/dysplastic changes. The bone marrow smear performed 12 months after transplant revealed an unsuspected diagnosis: a massive bone marrow infiltration with 


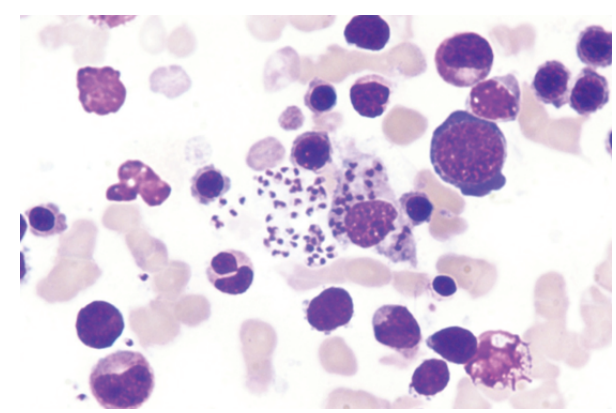

Figure 1: Photography of bone marrow smear showing massive bone marrow infiltration with amastigotes. Optical microscopy, Wright Giemsa stain, 100x magnification.

amastigotes-(Figure 1 optical microscopy, Wright Giemsa stain, 100x magnification). Reticuloendothelial cells had exuberant parasitic cytoplasmatic inclusions and a few images of erythrophagocytosis were present (Figure 1). The sample was sent to DNA PCR analysis and Leishmania infantum was identified. Previous bone marrow smears were reviewed and scarce parasites, not previously observed, were found in a smear performed 6 months after SCT. The donor had no history of visceral leishmaniasis. The patient was treated with a total dose of $24 \mathrm{mg} / \mathrm{kg}$ of liposomal amphotericin B, with clinical improvement and no signs of leishmania in the bone marrow. Five months later, the patient developed epigastric pain and duodenal biopsy revealed no evidence of graft versus host disease but the presence of inflammatory infiltrate with the presence of amastigotes in the macrophages was evident; a new bone marrow was performed and was positive for leishmania. The patient restarted liposomal amphotericin B and a prolonged maintenance treatment is planned.

\section{Discussion}

The classical presentation of visceral leishmaniasis includes fever, hepatoesplenomegalia, and cytopenias [1-5]. Visceral asymptomatic leishmaniasis is increasingly reported in patients living in endemic areas and in immunocompromised hosts [5-10]. This protozoon is endemic in the Mediterranean basin and patient reported sporadic contact with domestic dogs, which can be a reservoir. It is worth noting that dog leishmaniasis is reported to be common in the residence area of this patient. T-lymphocytes play a major role in the host defense from this parasitic infection and allogeneic bone marrow receipts under immunosuppression therapy are a particular susceptible population, especially in endemic areas [1]. There must be a high suspicion index evaluating this patients bone marrow samples as they can easily establish this diagnosis. This clinical case is remarkable for the absence of organomegaly, constitutional symptoms, and the massive invasion of bone marrow. We could not establish clearly the source of infection.

\section{Disclosure}

The paper has been read and approved by all named authors.

\section{Conflict of Interests}

The authors declare that they have no competing interests.

\section{References}

[1] L. Saporito, G. M. Giammanco, S. De Grazia, and C. Colomba, "Visceral leishmaniasis: host-parasite interactions and clinical presentation in the immunocompetent and in the immunocompromised host," International Journal of Infectious Diseases, vol. 17, no. 8, pp. e572-e576, 2013.

[2] World Health Organization, "Control of the leishmaniases," World Health Organization Technical Report Series 949, 2010.

[3] J. Alvar, I. D. Vélez, C. Bern et al., "Leishmaniasis worldwide and global estimates of its incidence," PLoS ONE, vol. 7, no. 5, Article ID e35671, 2012.

[4] N. Ezra, M. T. Ochoa, and N. Craft, "Human immunodeficiency virus and leishmaniasis," Journal of Global Infectious Diseases, vol. 2, pp. 238-257, 2010.

[5] S. Antinori, L. Schifanella, and M. Corbellino, "Leishmaniasis: new insights from an old and neglected disease," European Journal of Clinical Microbiology and Infectious Diseases, vol. 31, no. 2, pp. 109-118, 2012.

[6] M. C. Sharma, A. K. Gupta, V. N. R. Das et al., "Leishmania donovani in blood smears of asymptomatic persons," Acta Tropica, vol. 76, no. 2, pp. 195-196, 2000.

[7] S. Antinori, A. Cascio, C. Parravicini, R. Bianchi, and M. Corbellino, "Leishmaniasis among organ transplant recipients," The Lancet Infectious Diseases, vol. 8, no. 3, pp. 191-199, 2008.

[8] V. Pitini, A. Cascio, C. Arrigo, and G. Altavilla, "Visceral leishmaniasis after alemtuzumab in a patient with chronic lymphocytic leukaemia," British Journal of Haematology, vol. 156, no. 1, article 1, 2012.

[9] I. Simon, K. M. Wissing, V. del Marmol et al., "Recurrent leishmaniasis in kidney transplant recipients: report of 2 cases and systematic review of the literature," Transplant Infectious Disease, vol. 13, no. 4, pp. 397-406, 2011.

[10] A. Sirvent-von Bueltzingsloewen, P. Marty, E. Rosenthal et al., "Visceral leishmaniasis: a new opportunistic infection in hematopoietic stem-cell transplanted patients," Bone Marrow Transplantation, vol. 33, no. 6, pp. 667-668, 2004. 


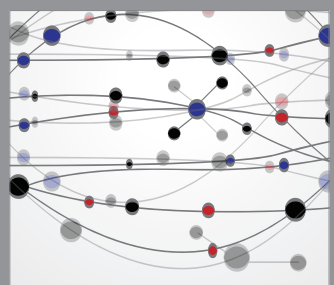

The Scientific World Journal
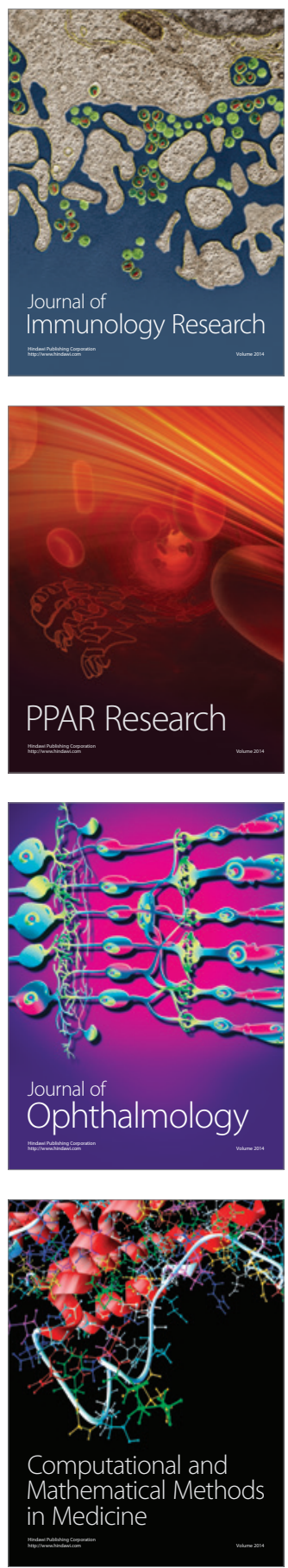

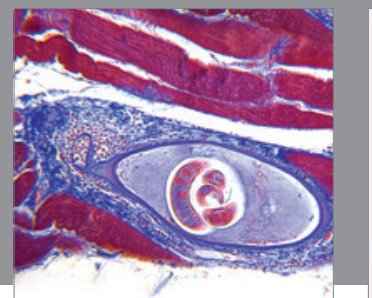

Gastroenterology

Research and Practice
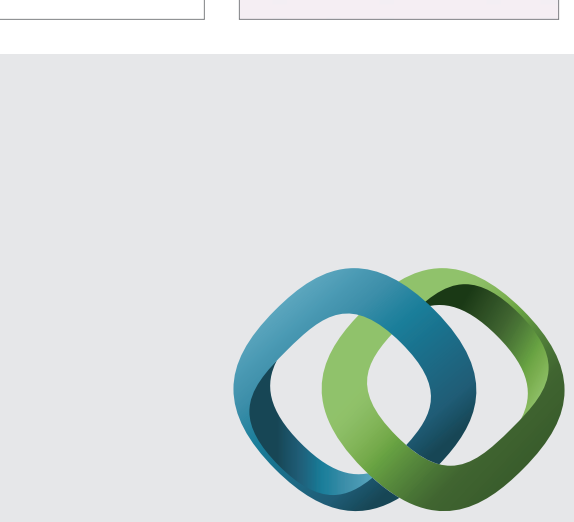

\section{Hindawi}

Submit your manuscripts at

http://www.hindawi.com
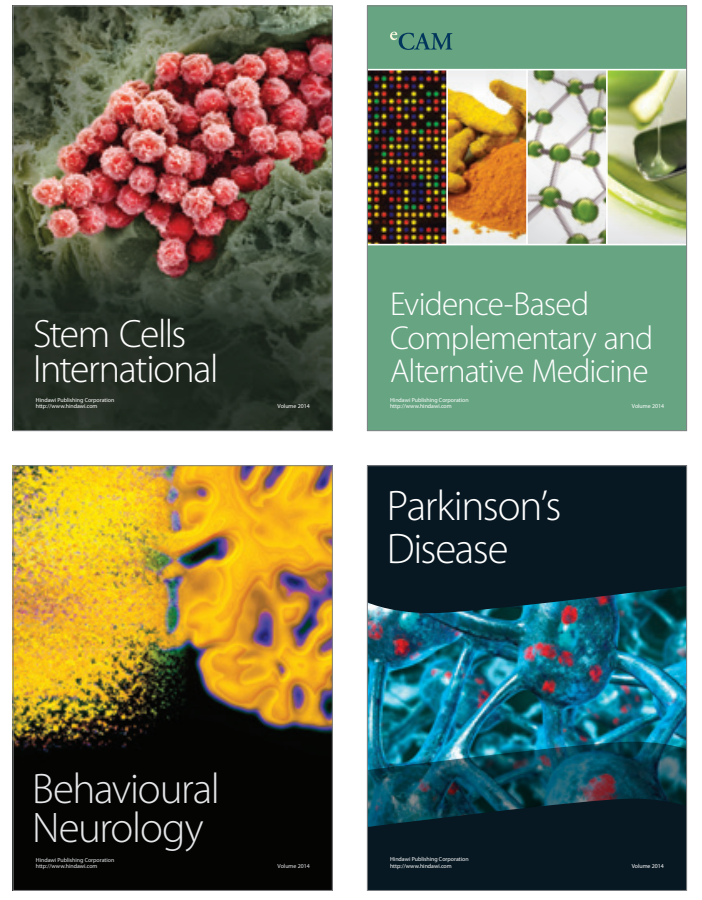
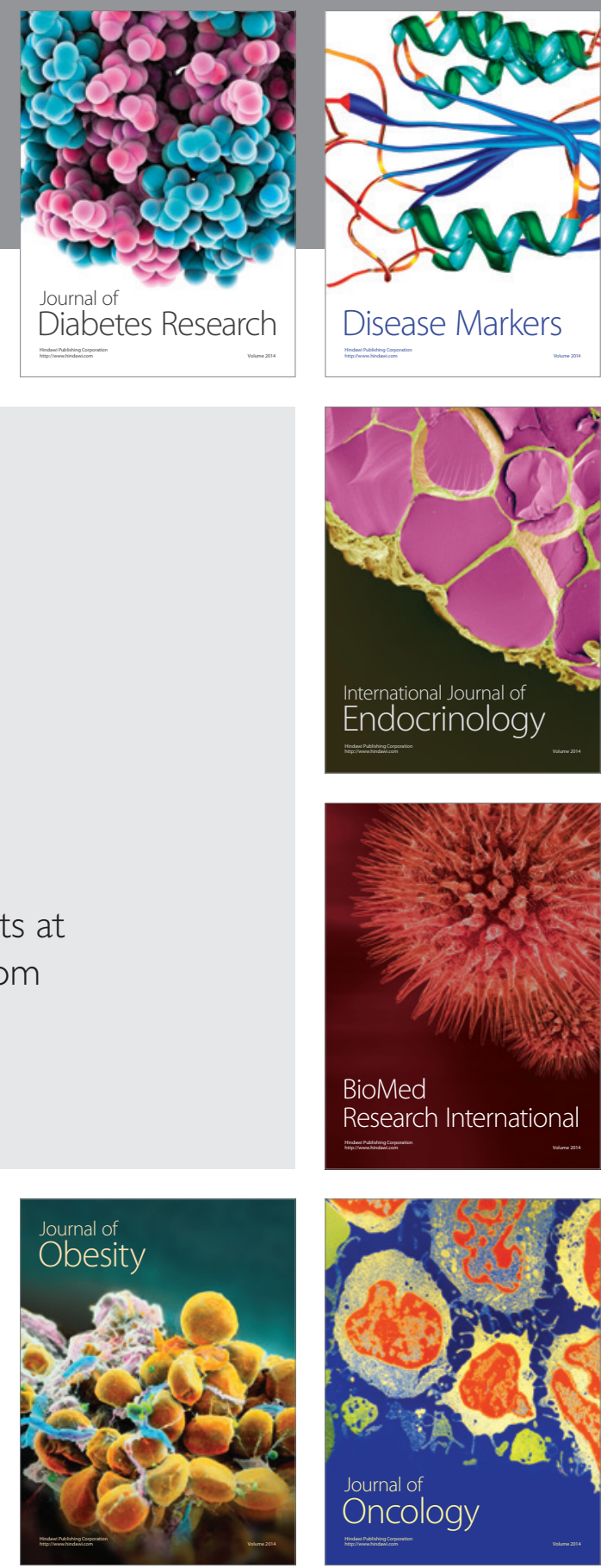

Disease Markers
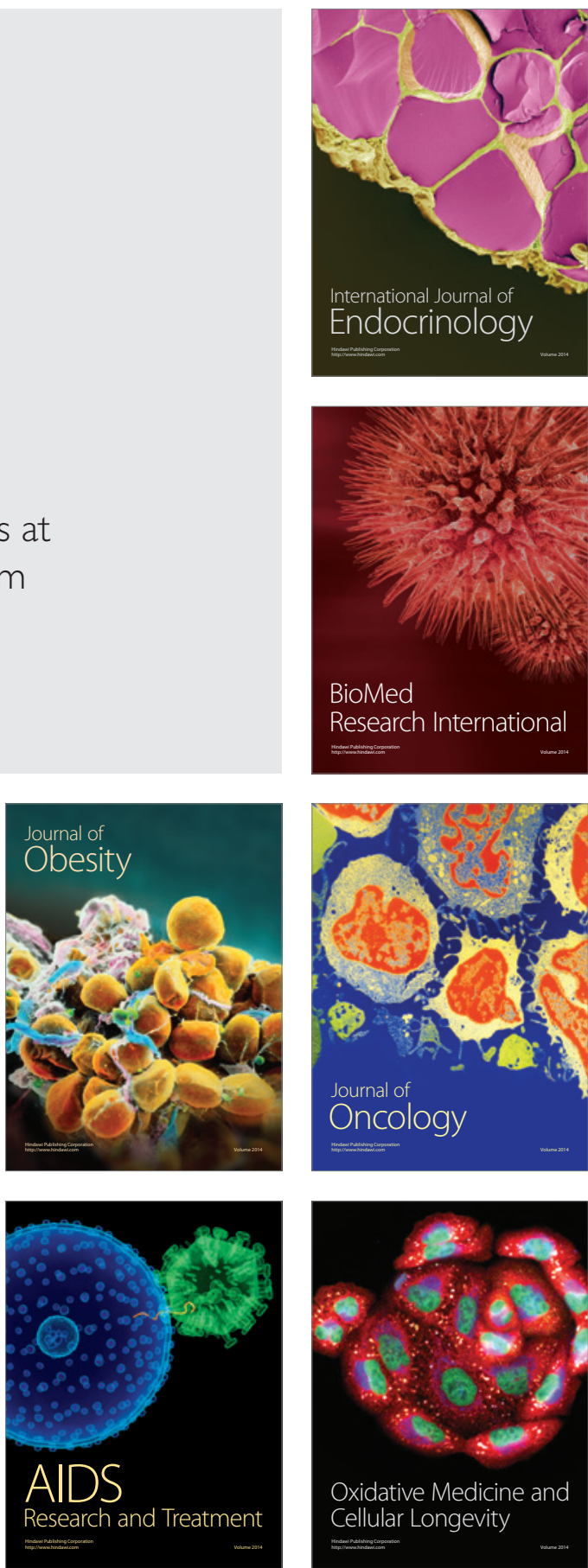